\title{
Correspondence
}

\section{Effects of different anesthetic techniques on enzymatic activities in ischemic femoral quadriceps}

To the Editor:

We present biochemical data relative to skeletal muscle oxidative metabolism of 22 consecutive healthy male patients undergoing anterior cruciate ligament (ACL) reconstruction under tourniquet ischemia. Ten patients were operated under spinal anesthesia (SA) with hyperbaric bupivacaine (SA - age: $24 \pm 4$ yr; height $177 \pm 4$ $\mathrm{cm}$; weight $71 \pm 9 \mathrm{~kg}$ ) and 12 under general anesthesia (GA) with sevoflurane (GA - age: $24 \pm 5 \mathrm{yr}$; height 173 $\pm 8 \mathrm{~cm}$; weight $74 \pm 0 \mathrm{~kg}$ ). The number of subjects included was limited by the modification of the surgical technique subsequent to the onset of the study.

A biopsy was taken from the femoral quadriceps muscle of each patient at three different times: immediately after the induction of anesthesia and ischemia (Tl-SA: $6 \pm 1 \mathrm{~min}$; GA: $6.4 \pm 1 \mathrm{~min}$ ); at the end of the surgical operation and before the deflation of the tourniquet (T2- SA: $91.8 \pm 4.4 \mathrm{~min}$; GA: $90.6 \pm 2.8$ min) and exactly eight minutes after the deflation of

TABLE Enzyme activities evaluated in the present study

\begin{tabular}{|c|c|c|c|c|c|}
\hline enzyme activities & S.A. & G.A. & T1 vs T2p-Value & T2 vs T3 P-Value & T3 vs T1 P-Value \\
\hline Citrate synthase (CS) & & & 0.000 & 0.319 & 0.000 \\
\hline $\mathrm{Tl}$ & $93.3(36.4)$ & $85.5(39)$ & & & \\
\hline $\mathrm{T} 2$ & $63.9(32.2)$ & $54.4(31.9)$ & & & \\
\hline $\mathrm{T} 3$ & $69.9(27.4)$ & $64.5(32.1)$ & & & \\
\hline \multicolumn{6}{|l|}{ NADH-ubiquinone oxidoreductase } \\
\hline (NADH-UQ oxidoreductase) & & & 0.015 & 0.000 & 0.396 \\
\hline $\mathrm{Tl}$ & $40.1(26.8)$ & $38.7(22.1)$ & & & \\
\hline $\mathrm{T} 2$ & $49.2(38.3)$ & $63.3(43.9)$ & & & \\
\hline $\mathrm{T} 3$ & $22.8(13.6)$ & $40.8(28)$ & & & \\
\hline Succinate dehydrogenase (SDH) & & & 0.002 & 0.007 & 0.927 \\
\hline T1 & $95.5(44.9)$ & $102.5(41.1)$ & & & \\
\hline $\mathrm{T} 2$ & $134.4(45)$ & $123.4(21.5)$ & & & \\
\hline $\mathrm{T} 3$ & $97.5(37.1)$ & $106.8(26.4)$ & & & \\
\hline \multicolumn{6}{|l|}{ NADH-cytochrome $\mathrm{c}$ reductase } \\
\hline rotenone insensible (CCR) & & & 0.000 & 0.000 & 0.457 \\
\hline $\mathrm{Tl}$ & $119.8(23.8)$ & $117.1(33.1)$ & & & \\
\hline $\mathrm{T} 2$ & $189.1(52.3)$ & $183.9(92.5)$ & & & \\
\hline $\mathrm{T} 3$ & $98.2(22.8)$ & $103.7(30.7)$ & & & \\
\hline Cytochrome oxidase (COX) & & & 0.000 & 0.000 & 0.091 \\
\hline $\mathrm{Tl}$ & $211.6(163.4)$ & $231.8(159.2)$ & & & \\
\hline $\mathrm{T} 2$ & $386.8(242.5)$ & $462.5(165.3)$ & & & \\
\hline $\mathrm{T} 3$ & $277.5(183.8)$ & $297.6(137.5)$ & & & \\
\hline Superoxide dismutase (Mn-SOD) & & & 0.958 & 0.995 & 0.981 \\
\hline $\mathrm{Tl}$ & $66.4(7.4)$ & $71.3(7.6)$ & & & \\
\hline $\mathrm{T} 2$ & $68.6(12.3)$ & $68.7(8.1)$ & & & \\
\hline $\mathrm{T} 3$ & $66.2(7.6)$ & $70.5(9.5)$ & & & \\
\hline Superoxide dismutase $(\mathrm{Cu}, \mathrm{Zn}-\mathrm{SOD})$ & & & 0.660 & 0.892 & 0.908 \\
\hline Tl & $142.6(15.6)$ & $150(18.1)$ & & & \\
\hline $\mathrm{T} 2$ & $144.4(16.3)$ & $143.6(18.8)$ & & & \\
\hline T3 & $140.9(12.8)$ & $150.3(13.4)$ & & & \\
\hline
\end{tabular}

Findings are presented as mean(SD). CS, NADH-UQ oxidoreductase, SDH, CCR, COX specific activities are expressed as mU/mg of protein; Mn-SOD and $\mathrm{Cu}, \mathrm{Zn}-\mathrm{SOD}$ specific activities are expressed as $\mathrm{U} \cdot \mathrm{g}^{-1}$ of fresh tissue.

The Kolmogorov-Smirnov test was used to check whether the distribution of data was normal, and the Hartley test was used to check the variance homogeneity of our findings. Statistical methods used were the Student's t test, the analysis of variance (ANOVA) by repeat measures and the post-hoc comparison Sheffè test, where appropriate. A $P$-value $<0.05$ was retained as statistically significant and all tests were two-sided. There were no significant differences between spinal (SA) and general (GA) anesthesia. 
the tourniquet for both groups (T3).

The specific activity of citrate synthase (CS), enzymes of the mitochondrial electron transfer chain ${ }^{1}$ and manganese-superoxide dismutase $(\mathrm{Mn}-\mathrm{SOD})^{2}$ were evaluated in the mitochondrial fraction; the specific activity of copper, zinc-superoxide dismutase $(\mathrm{Cu}, \mathrm{Zn}-\mathrm{SOD})^{2}$ was determined in the crude extract (Table).

We observed no significant biochemical differences between patients submitted to GA and those submitted to SA. A significant decrease in CS activity, perhaps due to mitochondrial dysfunction and swelling, ${ }^{3}$ was observed during ischemia (T2) from the T1 value, whereas an increase observed in CS activity at T3 suggests recovery due to reoxygenation.

An unexpected significant increase in the activity of the electron transfer chain enzymes was also observed during ischemia (T2) from the T1 values in both groups of patients. The significant reversal in this increase at T3 suggests the activation of a short-term regulatory mechanism during ischemia.

There were no significant changes in SOD enzyme activities during ischemia and reperfusion. This may be because, at T3, the muscle had not had enough time to produce enough free oxygen radicals to stimulate SOD activity.

The reversal at $\mathrm{T} 3$ of the increasing or decreasing tendencies at T2 of CS and electron transfer chain enzyme activities suggests the almost immediate onset of recovery from the combined effects of tourniquet induced ischemia and anesthesia. This should be of interest to orthopedic surgeons and to anesthesiologists.

The few data collected do not permit a firm conclusion on the effects of SA or GA. Since no difference was found between the two anesthetics in their effects on skeletal muscle oxidative metabolism, it may be that the main metabolic effects observed were due to ischemia rather than to anesthesia.

Felice M. Ramajoli MD

Manuela Verri PhD

Donatella De Amici MD

Federica Boschi PhD

Maurizia Dossena PhD

Mariana Catapano PhD

Isabella Ramajoli $\mathrm{PhD}$

Ornella Pastoris PhD

Pavia, Italy

\section{References}

1 Pastoris O, Boschi F, Verri M, et al. The effects of aging on enzyme activities and metabolite concentrations in skeletal muscle from sedentary male and female sub- jects. Exp Gerontol 2000; 35: 95-104.

2 Flohe L, Otting F. Superoxide dismutase assays.

Methods Enzymol 1984; 105: 93-104.

3 Whetzel TP, Stevenson TR, Sharman RB, Carlsen RC.

The effect of ischemic preconditioning on the recovery of skeletal muscle following tourniquet ischemia. Plast Reconstr Surg 1997; 100: 1767-75.

\section{Spinal anesthesia in an obese patient with osteogenesis imperfecta}

To the Editor:

A 33-yr-old gentleman (body mass index of 44) with a history of osteogenesis imperfecta (OI) type IV was scheduled for dynamic screw fixation of a right femoral fracture sustained during an epileptic fit. He had significant co-morbidities. These included noninsulin dependant diabetes mellitus, hypopitutarism, obesity, and learning difficulties. He had limited mobility but clinically had no significant symptoms or signs relevant to his cardiorespiratory system. His medications included thyroxine, hydrocortisone, benzodiazepine, sodium valproate, triazine, carbamazepine, testosterone, and sulphonylurea. A preoperative full blood count, platelets, and coagulation screen were normal. He had consistently low serum sodium (124 $\left.\mathrm{mmol} \cdot \mathrm{L}^{-1}\right)$, chloride $(90$ $\left.\mathrm{mmol} \cdot \mathrm{L}^{-1}\right)$, and calcium $\left(2.09 \mathrm{mmol} \cdot \mathrm{L}^{-1}\right)$. Such chronic electrolyte disturbances were due to the associated endocrine dysfunction.

As endotracheal intubation was expected to be difficult and hazardous, spinal block was chosen. Despite the associated kyphoscoliosis no difficulty was experienced finding the subarachnoid space using a midline approach with a 25 -gauge spinal needle. Three millilitres of L-bupivacaine and $10 \mu \mathrm{g}$ of fentanyl produced anesthesia to the level of T8 bilaterally. Temperature was monitored in addition to routine ASA monitoring. The operation lasted for three hours and the patient made an uneventful recovery.

Skeletal abnormalities of the lumbar spine, as in OI, are considered relative contraindications to spinal anesthesia. Associated cardiac lesions and a coagulopathy may also present problems. Management of the difficult airway due to abnormal cervical spine mobility, fragile teeth and the risk of mandibular and facial fractures are the risks associated with general anesthesia. The use of anticholinergics may exacerbate the risk of hyperthermia. Although general and epidural anesthesia have been reported in patients with OI, ${ }^{1,2}$ the use of spinal block is infrequent. This is possibly due 